\title{
EFEITO DO ALUMÍNIO SOBRE O CRESCIMENTO DE DUAS ESPÉCIES FLORESTAIS ${ }^{(1)}$
}

\author{
A. N. BEUTLE $R^{(2)}$, L. A. FERNANDE $S^{(3)} \&$ V. FAQUIN ${ }^{(4)}$
}

\begin{abstract}
RESUMO
Para estudar o efeito do Al no crescimento inicial de duas espécies flor estais, foi instalado um experimento em novembro de 1998, em solução nutritiva, em casa de vegetação do Departamento de Ciência do Solo da Universidade F ederal de Lavras. Após duas semanas em solução nutritiva diluída a 1/3 e sem Al, duas plantas de Moringa (Moringa oleifera) e duas de Angico (Anandenantha peregrina) foram transplantadas para vasos de 1,5 $\mathrm{L}$ e crescidas em solução nutritiva. Os teores de Al utilizados foram de 0,0; 2,5; 5,0; 7,5; e 10,0 mg L-1, com pH 4,0 $\pm 0,2$, ajustado diariamente durante 70 dias. Após este período, foi determinada a altura das plantas, as quais, posteriormente, foram divididas em parte aérea e raiz, para determinação da matéria seca e dos teores de $\mathrm{N}$ e $\mathrm{P}$. Os teores crescentes de Al reduziram progressivamente a altura das plantas e a produção de matéria seca das raízes nas duas espécies e da parte aérea no Angico. O teor de nitrogênio na Moringa diminuiu com o incremento nos teores de Al. O teor de fósforo na parte aérea da Moringa e do Angico diminui a partir de $5 \mathrm{mg} \mathrm{L}^{-1}$ de Al na solução nutritiva.
\end{abstract}

Termos de indexação: moringa, angico, toxidez, solução nutritiva.

\section{SUMMARY: ALUMINUM EFFECT ON THE GROWTH OF TWO FOREST SPECIES}

An experiment was carried out at theSoil ScienceDepartment of UniversidadeF ederal de Lavras, in Lavras (MG). in November 1998, to study the effect of aluminum on the initial growth of two forest species, under greenhouse conditions using a nutrient solution. After two weeks in dilute nutrient solution to $1 / 3$ and without aluminum, two Moringa (Moringa oleifera) and two Angico (Anandenantha peregrina) plants weretransplanted to $1.5 \mathrm{~L}$ pots, and grown in nutrient solution. The aluminum levels were $0.0,2.5,5.0,7.5$, $10.0 \mathrm{mg} \mathrm{L}^{-1}$, with pH $4.0 \pm 0.2$, adjusted daily during 70 days. Plant height was eval uated

(1) Trabal ho desenvolvido na Universidade Federal de Lavras - UFLA. Recebi do para publicação em fevereiro de 2000 e aprovado em julho de 2001.

(2) Doutorando do Departamento de Solos da Universidade Estadual Paulista - UNESP. CEP 14870-000 J aboticabal (SP). Bolsista da FAPESP. E-mail: amaurib@yahoo.com.br

(3) Professor do Núcleo de Ciências Agrárias da UniversidadeFederal de Minas Gerais - UFMG. Av. Osmani Barbosa s/n, CEP 39406006 Montes Claros (MG).

(4) Professor do Departamento de Ciência do Solo da Universidade Federal de Lavras - UFLA. Caixa Postal 37, CEP 37200-000 Lavras (MG). 
and plants were divided in aerial part and root, to determine dry matter and content of $\mathrm{N}$ and $P$. The increasing aluminum levels progressively reduced plant height and root dry matter production in both species, and theaerial part in theAngico plant. Nitrogen content in the Moringa plant reduced with increasing aluminum levels. Phosphorus content in the Moringa and Angico aerial parts reduced with aluminum levels above $5.0 \mathrm{mg} \mathrm{L}^{-1}$ in the nutrient solution.

Index terms: moringa, angico, toxicity, nutrient solution.

\section{NTRODUÇÃO}

A toxidez causada pelo alumínio éum dos fatores mais importantes que limitam o crescimento e a produção das plantas em sol os ácidos, principal mente em pH abaixo de 5,0. Visto que o baixo pH e a alta concentração de Al são condições encontradas na maioria dos solos tropicais, torna-se fundamental o conhecimento do comportamento de espécies florestais sob tais circunstâncias.

O Al trocável, em níveis tóxicos, causa anomalias e danos ao sistema radicular, resultando na expl oração de menor volume de sol o pelas plantas e prejudicando a absorção de água e nutrientes, conseqüentemente, ocorrem reduções no crescimento da parte aérea e na produção de matéria seca. O Al, em altas concentrações, acumula-se preferencialmente no sistema radicular das plantas, sendo pequena a quantidade translocada para a parte aérea (Wagatsuma, 1984; Massot et al., 1992). Entretanto, segundo Rhue \& Grogan (1977), várias plantas têm a capaci dade de acumular al tas concentrações deAl na parte aérea sem apresentar evidência de injúria ou toxidez por este elemento. Maiores teores de Al na raiz com relação à parte aérea foram observados nos estudos de Cal bo \& Cambraia (1980), em sorgo, Pavan \& Bingham (1982), em café, eOliveira \& Rena (1989), em mandioca.

A redução no crescimento das plantas causada pela toxidez de $\mathrm{Al}$, em solos ácidos, é considerada um dos fatores que mais limitam a produção (Mendonça et al., 1999). Pavan \& Binghan (1982), em cafeeiros, e Alves (1997), estudando espécies florestais, verificaram que o efeito inicial da toxidez do Al foi caracterizado por um retardamento no crescimento e desenvolvimento radicular, e, posteriormente, pela redução progressiva no crescimento da parte aérea, resultando em menor produção de matéria seca das raízes.

Braccini et al. (1998), estudando genóti pos de café (Coffea arabica), observaram que a presença do Al, em sol ução nutritiva, inibiu o crescimento das raízes e da parte aérea. Em plantas de fumo, observaramse um decréscimo no crescimento radicular e um aumento no raio médio das raízes na presença doAl em sol ução nutritiva, comprometendo o acúmulo de matéria seca (Rheinheimer et al., 1994).

As espécies de plantas e, ou, variedades de uma mesma espécie têm demonstrado comportamento diferencial quanto à susceptibilidade à toxidez de Al. A capacidade de manutenção da absorção e da transl ocação de fósforo (Foy, 1974; Cambraia et al., $1989,1991)$ e de el ementos minerais na presença do Al e absorção e translocação do próprio Al (Foy et al., 1978), a exclusão doAl do metabol ismo celular, a redução da atividade do Al pela sua complexação por ácidos orgâni cos exsudados pelas raízes (Mullette \& Hannon, 1974) ea absorção diferencial de cátions e ânions, em especial de $\mathrm{N}-\mathrm{NH}_{4}{ }^{+} \mathrm{e} \mathrm{N}-\mathrm{NO}_{3}{ }^{-}$, levando a alterações no meio de crescimento na presença de Al (Foy et al., 1965), são características relacionadas com a tolerância de espécies vegetais a este elemento.

O Al interfere de modo generalizado, quando em níveis tóxicos, na absorção e translocação de nutrientes, apresentando as plantas cultivadas em solos com toxidez de Al teores reduzidos de nutrientes na parteaérea (Cal bo\& Cambraia, 1980). A translocação de fósforo da raiz para a parte aérea pode ser comprometida pela presença do AI, podendo aparecer sintomas de sua deficiência. Esses dois elementos reagem e precipitam no apoplasto, ocorrendo, assim, o acúmulo de fósforo nas raízes (Cal bo \& Cambraia, 1980; Pavan \& Bingham, 1982). É possível queessa interação ocorra tanto na parede celular quanto externamente à plasmalema nas células da coifa (McCormick \& Borden, 1974), nos vacúol os de células das raízes (Macklon \& Sim, 1992) ou nos espaços intercelulares (Clarkson, 1966).

Teores de Al no solo acima de $1 \mathrm{mg} \mathrm{dm}^{-3}$ são considerados limitantes ao crescimento da maioria das culturas (Evans \& Kamprath, 1970). Vale et al. (1996), estudando 15 espécies florestais, observaram que o Angico amarel o (Peltophorium dubium) teve o crescimento radicular pouco afetado na presença de Al no solo na concentração de $1,48 \mathrm{mg} \mathrm{kg}^{-1}$. Alves (1997) observou que Senna mul tijuca eStenol obium stans apresentaram efeitos nocivos do Al na planta a partir de 5 e $20 \mathrm{mg} \mathrm{L}^{-1}$ de Al na solução nutritiva, respectivamente.

Há muitas informações sobre a toxidez de Al no crescimento das plantas; entretanto, poucos estudos foram feitos com a M oringa e o Angico, os quais são utilizados em programas de revegetação.

O objetivo do trabal ho foi avaliar o efeito do Al, em solução nutritiva, no crescimento inicial e nos teores de $\mathrm{N}$ e $\mathrm{P}$ em Moringa e Angico. 


\section{MATERIAL E MÉTODOS}

O presente trabalho foi realizado em casa de vegetação do Departamento de Ciência do Solo da Universidade Federal de Lavras, Lavras (MG), no período de novembro de 1998 a fevereiro de 1999.

O experimento foi efetuado em solução nutritiva, utilizando Moringa (Moringa ol eifera) e Angico vermelho (Anandenantha peregrina) ecincoteores de Al na solução adicionados na forma de cloreto: 0,0; 2,5; 5,0; 7,5 e 10,0 $\mathrm{mg} \mathrm{L}^{-1}$. A composição da solução nutritiva de Hoagland modificada por Valeet al. (1996), utilizada no experimento, éapresentada no quadro 1.

As sementes, após a quebra de dormência, foram germinadas em vermiculita. Quando as plantas estavam com \pm 3 pares defol has definitivas, plantas uniformes foram transferidas para bandejas que continham a sol ução de cultivo (Quadro 1), diluída a $1 / 3$ de força iônica. Após duas semanas nesta sol ução deadaptação, duas plantas uniformes quanto ao tamanho foram transplantadas, para cada vaso de 1,5 L, com a solução de cultivo e o Al equival ente ao tratamento.

$\mathrm{O}$ pH da solução foi mantido a 4,0 $\pm 0,2$ mediante ajustes diários com $\mathrm{HCl} 0,1 \mathrm{~mol} \mathrm{~L}^{-1}$ duranteo período de 70 dias, para minimizar as precipitações do Al. $\mathrm{O}$ nível das soluções nos vasos foi mantido pela adição diária deágua destilada. As soluções foram mantidas sob arejamento constante e trocadas a cada 14 dias.

Ao final do experimento, após a avaliação da altura, as plantas foram divididas em parte aérea e raiz, para determinar a matéria seca e os teores de $\mathrm{N}, \mathrm{P}$ eAl. O N foi determinado pel o método semimicro Kjeldahl (Malavolta et al., 1989). Após a digestão nítrico-perclórica, o P foi analisado por colorimetria com azul demolibdênio, eoAl por espectrofotometria de absorção atômica.

O delineamento experimental foi inteiramente casual izado, com quatro repetições. Os dados foram submeti dos à análise da variância eforam ajustadas equações de regressão entre os teores de $\mathrm{Al}$ e as variáveis avaliadas.

\section{Quadro 1. Concentração de nutrientes da solução nutritiva}

\begin{tabular}{cccc}
\hline Nutriente & \multicolumn{3}{c}{ Nutriente } \\
\hline & $\mathrm{mmol} \mathrm{L}^{-1}$ & & $\mu \mathrm{mol} \mathrm{L}-1$ \\
$\mathrm{~N}$ & 4,0 & $\mathrm{Mn}$ & 6,13 \\
$\mathrm{P}$ & 0,065 & $\mathrm{Zn}$ & 0,513 \\
$\mathrm{~K}$ & 4,0 & $\mathrm{Cu}$ & 0,215 \\
$\mathrm{Ca}$ & 1,53 & $\mathrm{~B}$ & 31,0 \\
$\mathrm{Mg}$ & 1,0 & $\mathrm{Mo}$ & 0,074 \\
$\mathrm{~S}$ & 3,0 & $\mathrm{Fe}^{(1)}$ & 42,3 \\
\hline
\end{tabular}

(1) Fe-EDTA.

\section{RESULTADOS E DISCUSSÃO}

A altura das plantas de Moringa e Angico diminuiu linearmente com o incremento no teor de Al na solução nutritiva (Figura 1), o que corrobora os resultados de Pavan \& Binghman (1982) e Braccini et al. (1998), mostrando que as espécies florestais estudadas foram sensíveis a partir do menor teor deAl utilizado na solução nutritiva.

O decréscimo na altura de plantas pode, segundo Cambraia et al. (1989), ser resultante da limitação na absorção de nutrientes pelas plantas, bem como da interferência na aquisição e no metabolismo nitrogenado, havendo diminuição na absorção e redução do nitrato em raízes, quando oAl se encontra em teores tóxicos. Ainda, o Al pode afetar o crescimento da parte aérea por meio da inibição na biossíntese de citocinina, hormônio que estimula a divisão cel ular nas raízes e subseqüente decréscimo na sua translocação para os sítios de ação (Pan et al., 1989). Rengel (1992) afirma que o Al também dificulta o crescimento da parede celular, necessário ao al ongamento celular, pel o desl ocamento do Ca das pontes deligaçãol ocalizadas na sua camada interna, diminuindo o crescimento das plantas.

As duas espécies florestais estudadas apresentaram comportamento semelhante em relação à produção de matéria seca das raízes, sendo esta restringida a partir de $2,5 \mathrm{mg} \mathrm{L}^{-1}$ de Al na solução nutritiva (Figura 1). Alves (1997) constatou que Senna multijuca e Stenolobium stans foram susceptíveis aoAl na solução nutritiva, a partir de 5 e $20 \mathrm{mg} \mathrm{L}^{-1}$, respectivamente, e Mendonça et al. (1999) verificaram decréscimo de 50\% na matéria seca das raízes de maracujá, no teor de $5 \mathrm{mg} \mathrm{L}^{-1}$ de Al em sol ução nutritiva. Valeet al. (1996) observaram que o crescimento radicular do Angico Amarelo (Peltophorium dubium) foi pouco afetado na concentração deAI na sol ução do solo de $1,48 \mathrm{mg} \mathrm{kg}^{-1}$.

A produção de matéria seca das raízes diminuiu com o incremento da concentração de AI na solução nutritiva, nas duas espécies, tendo o Angico apresentado decréscimo linear da produção de matéria seca da parte aérea (Figura 1), concordando com os resultados de Calbo \& Cambraia (1980), Alves (1997) e Braccini et al. (1998). Segundo Cal bo \& Cambraia (1980), isto deve-se à alteração na absorção etranslocação de nutrientes da raiz para a parte aérea. Outro aspecto, observado nas duas espécies florestais, foi a menor produção de matéria seca das raízes comparada à da parte aérea, indicando que o efeito tóxico do Al manifesta-se mais intensamente no sistema radicular, conforme também constatado por Pavan \& Bingham (1982) e Alves (1997).

A toxidez de Al manifesta-se inicialmente no sistema radicular e, posteriormente, ocorre redução progressiva do crescimento da parte aérea com o 

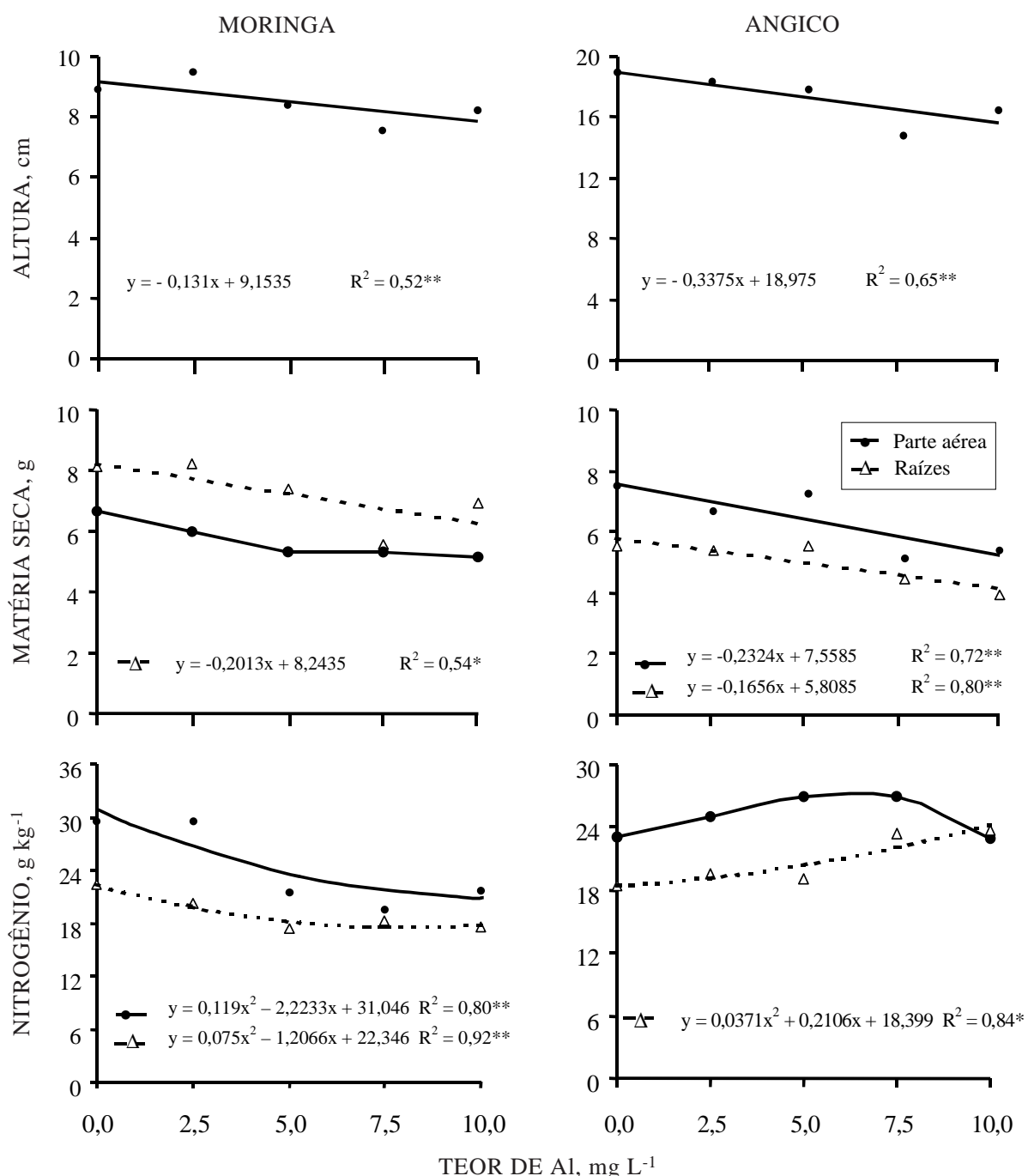

\section{Figura 1. Altura, matéria seca e teor de $\mathrm{N}$ da parte aérea e das raízes da Moringa e do Angico em diferentes teores de Al na solução nutritiva.}

incremento no nível deAl (Braccini et al., 1998), fato este que permite inferir que a Moringa foi mais tolerante, comparada ao Angico, pois a produção de matéria seca da parte aérea da Moringa não foi significativamenterestringida até $10,0 \mathrm{mg} \mathrm{L}^{-1}$ deAl na solução nutritiva.

O teor de $\mathrm{N}$ na matéria seca da parte aérea e das raízes da Moringa diminuiu com o incremento na concentração deAl na solução nutritiva (Figura 1), o que corrobora com os resultados de Gomes et al. (1985) e Cambraia et al. (1990). O Al, quando é encontrado em teores tóxicos, interfere na aquisição e no metabol ismo nitrogenado, havendo dimi nuição na absorção, translocação e redução do nitrato em raízes (Gomes et al., 1985; Cambraia et al., 1989). No Angico, ocorreu incremento do teor de $\mathrm{N}$ na matéria seca das raízes com o incremento na concentração de Al na solução nutritiva, e na parte aérea não houve efeito do Al no teor de N.
O teor de $\mathrm{P}$ na parteaérea da M oringa e doAngico aumentou inicialmente até $5 \mathrm{mg} \mathrm{L}^{-1}$, diminuindo a seguir com o incremento no teor de Al na solução nutritiva (Figura 2), concordando com os estudos de Pavan \& Binghman (1982), que verificaram decréscimo na absorção e translocação de $\mathrm{P}$ para a parte aérea com o incremento do teor de Al na solução nutritiva. Alves (1997) verificou que em Stenol obi um stans até o teor de $10,0 \mathrm{mg} \mathrm{L}^{-1}$ deAl na solução nutritiva, não houve alteração na concentração de fósforo na planta. Segundo Foy (1988), a toxidez de Al geralmente reduz a concentração de $\mathrm{P}$ na parte aérea, mas o grau de interferência varia com a espécie e com o genótipo da planta. A capacidade de manutenção da absorção e da translocação deP éum mecanismo detolerância das plantas ao Al (Cambraia et al., 1991).

O teor deP na matéria seca das raízes da Moringa diminuiu a partir de $5 \mathrm{mg} \mathrm{L}^{-1}$ de Al na solução 

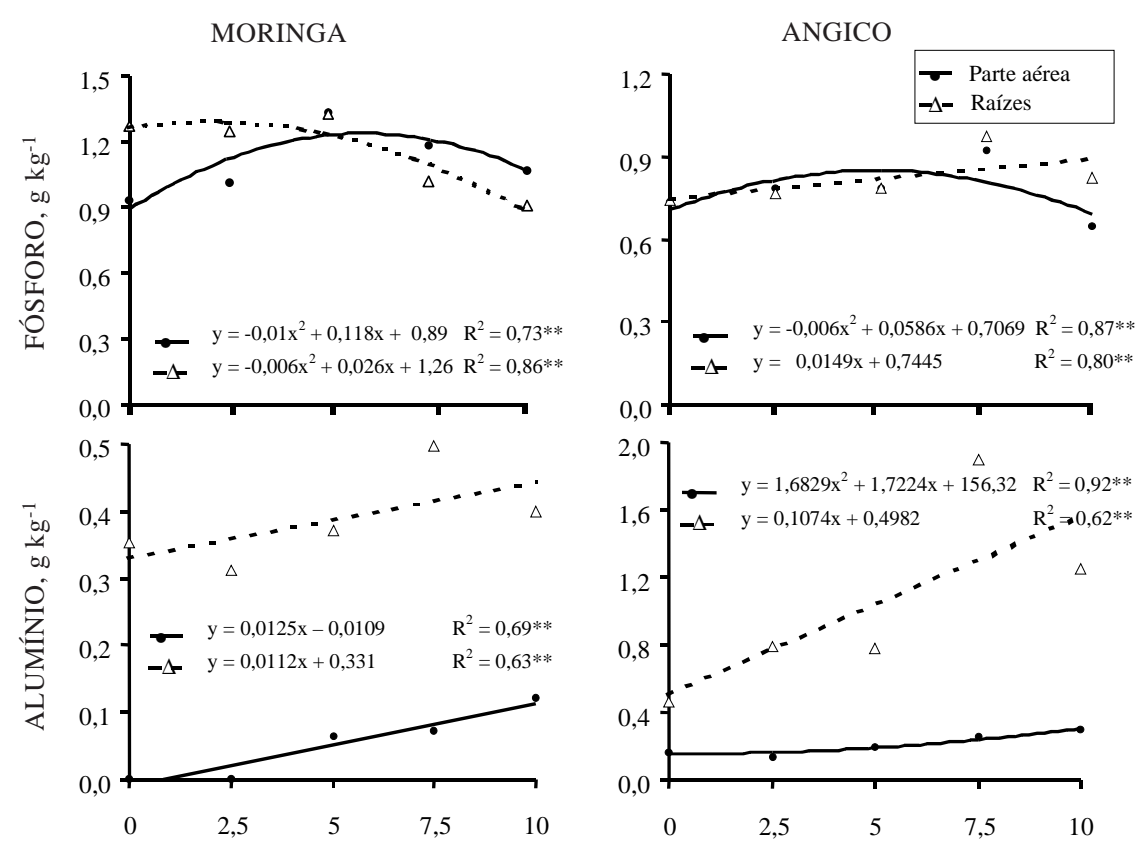

TEOR DE Al, mg L ${ }^{-1}$

Figura 2. Teores de P eAI na matéria seca da parte aérea e das raízes da Moringa e do Angico em di ferentes teores de Al na solução nutritiva.

nutritiva e, no Angico, ocorreu incremento progressivo do teor deP nas raízes e reduçãona parte aérea, com aumento dos teores de Al na solução nutritiva (Figura 2). Segundo Calbo \& Cambraia (1980), o incremento do teor de $P$ nas raízes com o incremento do Al na solução nutritiva é devido a reações de precipitação do P com Al na superfície ou no interior das células das raízes. Assim, o incremento do teor de $\mathrm{P}$ na matéria seca das raízes doAngico possivel mente está relacionado com o al to teor deAl nas raízes (Figura 2).

O teor deAl na matéria seca da parteaérea e das raízes das espécies aumentou com o incremento no teor do Al na solução nutritiva (Figura 2). Entretanto, o teor de Al na raiz foi superior ao da parte aérea, corroborando os resultados de Calbo \& Cambraia (1980), Pavan \& Bingham (1982), Oliveira \& Rena (1989) e Mendonça et al. (1999). Segundo Wagatsuma (1984) e Massot et al. (1992), o Al acumula-se preferencialmente no sistema radicular, sendo pequenas quantidades deAI translocadas para a parte aérea das plantas, em decorrência de reações de precipitação do Al com ânions na raiz.

Visto que oAl interfere na absorção etranslocação de nutrientes (Foy, 1988), na divisão celular (Pan et al., 1989) e na el ongação celular (Rengel, 1992), o maior teor deAl na matéria seca das raízes doAngico possivelmente explica a redução progressiva na produção de matéria seca da parte aérea com o incremento na concentração de Al na solução nutritiva, podendo-se inferir que o Angico foi mais sensível ao Al em solução nutritiva.

\section{CONCLUSÕES}

1. A toxidez de Al na Moringa e no Angico caracterizou-se pela redução na altura das plantas e na produção de matéria seca e pelo aumento no teor deAl nas plantas.

2. A Moringa e o Angico apresentaram efeitos nocivos do Al em solução nutritiva a partir de $2,5 \mathrm{mg} \mathrm{L}^{-1}$ de Al, tendo no Angico ocorrido redução da produção da matéria seca da parte aérea.

3. O Al na solução nutritiva reduziu os teores de $\mathrm{N}$ e $\mathrm{P}$ na parte aérea das duas espécies.

\section{LITERATURA CITADA}

ALVES, R.M.N. Comportamento diferencial ao Al em solução nutritiva de cultivares de feijão (Phaseolus vulgaris L.), sensível e tolerante e das espécies florestais Cássia Verrugosa (Senna multijuga (L.C. Rich.)) e I pê Mirin (Stenolobiun stans (J un.)). Lavras, Universidade Federal de Lavras, 1997. 92p. (Tese de Mestrado)

BRACCINI, M.C.L.; MARTINEZ, H.E.P.; PEREIRA, P.R.G.; SAMPAIO, N.F. \& SILVA, E.A.M. Tolerância de genótipos de cafeeiro ao Al em solução nutritiva. I. Crescimento e desenvol vimento da parte aérea esistema radicular. R. Bras. Ci. Solo, 22:435-442, 1998.

CALBO, A.G. \& CAMBRAIA, J . Efeito do Al sobre a composição mineral de dois cultivares de sorgo (Sorghum bicolor $L$. Moench). R. Ceres, 27:369-378, 1980. 
CAMBRAIA, J .; GOMES, M.M.S.; SANT'ANNA, R. \& ESTEVÃO, M.M. Efeito de diferentes níveis de Al na solução nutritiva sobre a composição da fração nitrogenada em sorgo. R. Bras. Fisiol. Veg., 2:47-52, 1990.

CAMBRAIA，J .; PIMENTA， J.A.; ESTEVÃO, M.M.\& SANT'ANNA, R. Aluminum effects on nitrate uptake and reduction in sorghum. J. Plant. Nutr., 12:1435-1445, 1989.

CAMBRAIA, J .; SILVA, M.A.; CANO, M.A.O. \& SANT'ANNA, R. Método simples para a avaliação de cultivares de sorgo quanto a tolerância aoAl. R. Bras. Fisiol. Veg., 3:87-95, 1991.

CLARKSON, D.T. Effect of aluminum on the uptake and metabolism of phosphorus by barley seedlings. Plant Physiol., 41:165-172, 1966.

EVANS, C.E. \& KAMPRATH, E.J . Lime response as related to percent Al saturation, solution Al, and organic matter content. Proc.Soil Sci. Soc. Am., 34:893-896, 1970.

FOY, C.D. Effects of aluminum in plant growth. In: CARSON, E.W., ed. The plant root and its environment. Charlottesville, University Press of Virginia, 1974. p.601-642.

FOY, C.D.; BURNS, G.R.; BROWN, J.C. \& FLEMING, A.L. Differential aluminum tolerance of two wheat varieties associated with plant induced $\mathrm{pH}$ changes around the roots. Proc. Soil Sci. Soc. Am., 29:64-67, 1965.

FOY, C.D.; CHANEY, R.L. \& WHITE, M.C. The physiology of metal toxicity in plants. An. Rev. Plant Physiol., 29:511566, 1978.

FOY, C.D. Plant adaptation to acid aluminum-toxic soils. Comm. Soil Sci. Plant Anal., 19:959-987, 1988

GOMES, M.M.S.; CAMBRAIA, J .; SANT'ANNA. R. \& ESTEVÃO, M.M. Aluminum effects on uptake and translocation of nitrogen in sorghum (Sorghum bi col or L. Moench). J. Plant Nutr., 8:457-465, 1985.

MACKLON, A.E.S. \& SIM, A. Modifying effects of a non-toxic level of aluminium on phosphate fluxes and compartmentation in root cortex cells of intact ryegrass seedlings. J. Exp. Bot., 43:1483-1490, 1992.

MALAVOLTA, E.; VITTI, G.C. \& OLIVEIRA, S.A. Avaliação do estado nutricional das plantas. Piracicaba, POTAFOS, 1989. 201p.
MASSOT, N.; POSCHENRIEDER, C. \& BARCELÓ, J . Differential response of three bean (Phaseol us vulgaris L.) cultivars to aluminum. Acta Bot. Neerl., 41:293-298, 1992.

MCCORMICK, L.H. \& BORDEN, F.Y. The occurrence of aluminum phosphate precipitate in plant roots. Proc. Soil Sci. Soc. Am., 38:931-934, 1974.

MENDONÇA, R.M.N.; COELHO, A.F.S.; MARTINEZ, H.E.P.; FONTES, P.C.R. \& PEREIRA, P.R.G. Resposta de mudas de maracujá-amarelo (Passiflora edulis Sims. F. Flavicarpa Deg.) cultivadas em solução nutritiva, a diferentes níveis de Al. R. Ceres, 46:357-370, 1999.

MULLETTE, K.J . \& HANNON, J.N. I nsoluble phosphorus usage by Eucalyptus. Plant Soil, 41:199-205, 1974.

OLIVEIRA, L.E.M. \& RENA, A.B. Influência do Al sobre o comportamento nutricional de cultivares de mandioca em solução nutritiva. Pesq. Agropec. Bras., 24:1119-1130, 1989.

PAN, W.L.; HOPKINS, A.G. \& J ACKSON, W.A. Aluminum inhibition of shoot lateral branches of Glycine max and reversal by exogenous cytokinin. Plant Soil, 120:1-9, 1989.

PAVAN, M.A. \& BINGHAM, F.T. Toxidez de Al em cafeeiros cultivados em solução nutritiva. Pesq. Agropec. Bras., 17:1293-1302, 1982

RENGEL, Z. Role of calcium in aluminum toxicity. New Phytol., 121:499-513, 1992.

RHEINHEIMER, D.S.; PETRY, C.; KAMINSKI, J \& BARTZ, H.R Influência do estresse de Al em plantas de fumo: I. Efeito no sistema radicular, na absorção de fósforo e cálcio e na produção de matéria seca. R. Bras. Ci. Solo, 18:63-68, 1994.

RHUE, R.D. \& GROGAN, C.O. Screening corn for Al tolerance using different $\mathrm{Ca}$ and $\mathrm{Mg}$ concentrations. Agron. J ., 69:755760, 1977

VALE, F.R.; FURTINI NETO, A.E.; RENÓ, N.B.; FERNANDES, L.A. \& RESENDE A.V. Crescimento radicular de espécies florestais em solo ácido. Pesq. Agropec. Bras., 31:609-616, 1996.

WAGATSUMA, T. Characteristics of upward translocation of aluminum in plants. Soil Sci. Plant Nutr., 30:345-358, 1984. 